\section{Identification and Classification of Main Iranian Olive Cultivars Using Microsatellite Markers}

\author{
Zahra Noormohammadi \\ National Institute of Genetic Engineering and Biotechnology (NIGEB), \\ Tehran, Iran; and the Genetic Department, Science Faculty, Tarbiat \\ Modarres University, Tehran, Iran
}

Mehdi Hosseini-Mazinani ${ }^{1}$

National Institute of Genetic Engineering and Biotechnology (NIGEB), Molecular Genetics, Shahrak-e Pajoohesh, Tehran, 14155-6343, Iran

Isabel Trujillo and Luis Rallo

Agronomy Department, Cordoba University, Cordoba, Spain

Angjelina Belaj

C.I.F.A. "Alameda del Obispo," IFAPA, Cordoba, Spain

\author{
Majid Sadeghizadeh \\ Genetic Department, Science Faculty, Tarbiat Modarres University, Tehran, \\ Iran
}

Additional index words. genetic diversity, Iranian olive cultivars, microsatellite markers

\begin{abstract}
Numerous olive cultivars are cultivated in Iran, mainly in the north. Ninetytwo accessions belonging to 10 main olive cultivars were screened by 13 microsatellite markers revealing high genetic variability both within and between cultivars. In total, 72 alleles were detected with a mean number of 5.5 alleles per locus. Twenty-four unique allelic patterns were observed, whereas six genotypes showed 15 unique alleles. Heterozygosity ranged from 0.00 to 0.98 , whereas the mean number of discrimination power and polymorphic information content were 0.55 and 0.54 , respectively. The combination of 5 simple sequence repeat markers made discrimination of $84 \%$ of all accessions included in the study possible. The existence of homonyms, synonyms, or mislabeling as well as intracultivar polymorphism was revealed by allele differences between accessions of the same denomination. The phenogram showed variability among as well as between some cultivars, but most accessions with the same generic names were grouped together.
\end{abstract}

Olive (Olea europaea L.) is as an important oil-producing crop in the Mediterranean region whose domestication occurred during the Chololithic period (5700-5500 years BC) in the Near-East (Zohary and Hopf, 1994). It has been suggested that the olive was introduced into the Mediterranean Basin from the Middle East or Eastern Africa (Chevalier, 1948; Green and Wickens, 1989; Turrill, 1951).

Archaeological findings revealed that olive cultivation in Iran dates back 2000 years ago (Sadeghi, 1992). At present, the old commercial olive orchards are located mainly in the north of Iran and more than $85 \%$ of olive production belongs to these

\footnotetext{
Received for publication 10 Apr. 2007. Accepted for publication 24 June 2007.

This research has been supported by NIGEB, Iran (grant 241).

We thank the Unit of Genomics of the Central Service for Research Support of the University of Córdoba (Spain) for its services.

${ }^{1}$ To whom reprint requests should be addressed; e-mail Hosseini@nrcgeb.ac.ir
}

regions. In the last 10 years, olive plantation has grown in several provinces and currently, olive cultivation covers more than 100,000 ha in Iran. The total olive production was $\approx 60,000$ tons in 2005 (Zeinanloo, 2006). Although a large number of olive accessions are growing in Iran, there have been few limited reports on morphological, cytogenetic, and molecular characteristics of these accessions (Hosseini-Mazinani et al., 2004; Omrani-Sabbaghi et al., 2007; Samaee et al., 2003; Sheidai et al., 2007).

Initial exploration surveys throughout the country found 10 main traditional olive cultivars (Sadeghi, 1992). More recently, investigations based on International Olive Council morphological descriptors have found a considerable variation within Iranian olive cultivars (Hosseini-Mazinani et al., 2004). The use of morphological markers has been useful for olive germplasm characterization and identification in many olive-growing countries (Cantini et al., 1999; Rallo et al., 2005). However, discrimination of varieties based on morphology evaluation is limited by the effect of environmental conditions, the need for extensive observations of mature plants, and the requirement of very well-trained staff (Belaj et al., 2001). Therefore, more comprehensive studies using reliable markers are needed to gain a better understanding of the level and distribution of genetic diversity in olive cultivars, which may be of use in cultivar identification.

In recent years, molecular markers such as isozymes (Trujillo et al., 1995) randomly amplified polymorphic DNA (RAPD) (Belaj et al., 2001; Besnard et al., 2001; Mekuria et al., 1999; Wiesman et al., 1998), and amplified fragment length polymorphism (Angiolillo et al., 1999) have been increasingly used to characterize and distinguish the olive cultivars.

As a result of their multiallelic hypervariability, codominant nature, high information content, and amenability to automation, microsatellites are becoming one of the most popular and reliable marker systems for genetic characterization of varieties, genetic diversity, plant breeding programs, genetic map development, and linkage analysis (Morgante and Olivieri, 1993; Powell et al., 1996; Rafalski et al., 1996). Microsatellites have also been proven to be very suitable markers for fingerprinting and revealing the genetic diversity in olive cultivars (Bandelj et al., 2002; Belaj et al., 2004; Cipriani et al., 2002; De la Rosa et al., 2002; Diaz et al., 2006; Khadari et al., 2003; Rallo et al., 2000; Sefc et al., 2000).

The present study aims at characterizing, by the use of microsatellite markers, main Iranian olive cultivars in three north provinces of Gilan, Zanjan, and Ghazvin, which are considered the most important regions of olive cultivation in Iran. We also try to verify homonymy (one denomination for several genotypes), synonymy (one genotype with several denominations), intracultivar polymorphism, and mislabeling. To our knowledge, this is the preliminary report on the identification and classification of the main Iranian olive cultivars in detail by means of microsatellite markers.

\section{Materials and Methods}

Plant materials and DNA extraction. A panel of 92 accessions belonging to the 10 major Iranian olive cultivars was used in the molecular study (Table 1). Trees were sampled randomly from eight different locations selected in 3 provinces of Gilan, Zanjan, and Ghazvin so as to be representative of the majority of Iranian olive varieties (Fig. 1). Total genomic DNA was extracted from fresh leaves using the CTAB method of Murry and Tompson (1980) with modification described by De la Rosa et al. (2002).

Microsatellite assay. To reduce the number of replication of each genotype, screening was performed on 92 olive accessions by using five high polymorphic simple sequence repeat (SSR) markers (ssrOeUADCA3,ssrOeUA-DCA9, ssrOeUA-DCA16, ssrOeUA-DCA18, and UDO99-043), which have been shown to be efficient for cultivar 
Table 1. Cultivar accession included in the study, English translation, the number of studied trees per accession or source of material, geographical diffusion and use of fruit, and ordering number $(\mathrm{Nr})$.

\begin{tabular}{|c|c|c|c|c|c|c|}
\hline $\mathrm{Nr}$ & $\begin{array}{c}\text { Cultivar } \\
\text { accession }\end{array}$ & $\begin{array}{l}\text { English } \\
\text { translation }\end{array}$ & $\begin{array}{c}\text { No. } \\
\text { of trees }\end{array}$ & $\begin{array}{c}\text { Source } \\
\text { of materials }\end{array}$ & $\begin{array}{l}\text { Geographical } \\
\text { diffusion }\end{array}$ & $\begin{array}{l}\text { Use of } \\
\text { fruits }\end{array}$ \\
\hline 7 & Dakal & Olive of Dakal & 4 & Research Garden & Gilan & \\
\hline 2 & Dezful & Olive of Dezful & 3 & Research Garden & Gilan & $\mathrm{O}^{z} \& \mathrm{~T}^{\mathrm{z}}$ \\
\hline 3 & Fishomi & Olive of Fishom & 6 & Research Garden & Gilan & O\&T \\
\hline 4 & Geloleh & Round olive & 4 & Harzebil & Gilan & $\mathrm{O}$ \\
\hline 5 & Geloleh & Round olive & 7 & Ettka Garden & Gilan & $\mathrm{O}$ \\
\hline 6 & Geloleh & Round olive & 1 & BahramAbad & Ghazvin & $\mathrm{O}$ \\
\hline 7 & Geloleh & Round olive & 3 & Manjil & Gilan & $\mathrm{O}$ \\
\hline 8 & Geloleh & Round olive & 3 & Motahari Garden & Zanjan & $\mathrm{O}$ \\
\hline 9 & Khara & No translation & 2 & Ettka Garden & Gilan & $\mathrm{O}$ \\
\hline 10 & Khorma zeitoon & Date-shaped olive & 7 & Harzebil & Gilan & O\&T \\
\hline 11 & Khorma zeitoon & Date-shaped olive & 1 & Motahari Garden & Zanjan & O\&T \\
\hline 12 & Khorma zeitoon & Date-shaped olive & 1 & Anjilak & Gilan & O\&T \\
\hline 13 & Mari & Sneaky olive & 2 & Motahari Garden & Zanjan & O\&T \\
\hline 14 & Mari & Sneaky olive & 2 & Research Garden & Gilan & O\&T \\
\hline 15 & Mari & Sneaky olive & 2 & Ettka Garden & Gilan & O\&T \\
\hline 16 & Rowghani & Oily olive & 3 & Research Garden & Gilan & $\mathrm{O} \& \mathrm{~T}$ \\
\hline 17 & Rowghani & Oily olive & 2 & BahramAbad & Ghazvin & O\&T \\
\hline 18 & Rowghani & Oily olive & 4 & Vakhman & Ghazvin & O\&T \\
\hline 19 & Rowghani & Oily olive & 3 & Motahari Garden & Zanjan & O\&T \\
\hline 20 & Rowghani & Oily olive & 2 & Ettka Garden & Gilan & O\&T \\
\hline 21 & Shengeh & No translation & 1 & Ettka Garden & Gilan & O\&T \\
\hline 22 & Shengeh & No translation & 16 & Research Garden & Gilan & O\&T \\
\hline 23 & Shengeh & No translation & 2 & Manjil & Gilan & $\mathrm{O} \& \mathrm{~T}$ \\
\hline 24 & Zard & Yellow & 4 & Research Garden & Gilan & O\&T \\
\hline 25 & Zard & Yellow & 4 & Ettka Garden & Gilan & O\&T \\
\hline 26 & Zard & Yellow & 3 & Motahari Garden & Zanjan & O\&T \\
\hline
\end{tabular}

${ }^{\mathrm{z}} \mathrm{O}=$ oil; $\mathrm{T}=$ table olive; $\mathrm{O \& T}=$ oil and table olive.
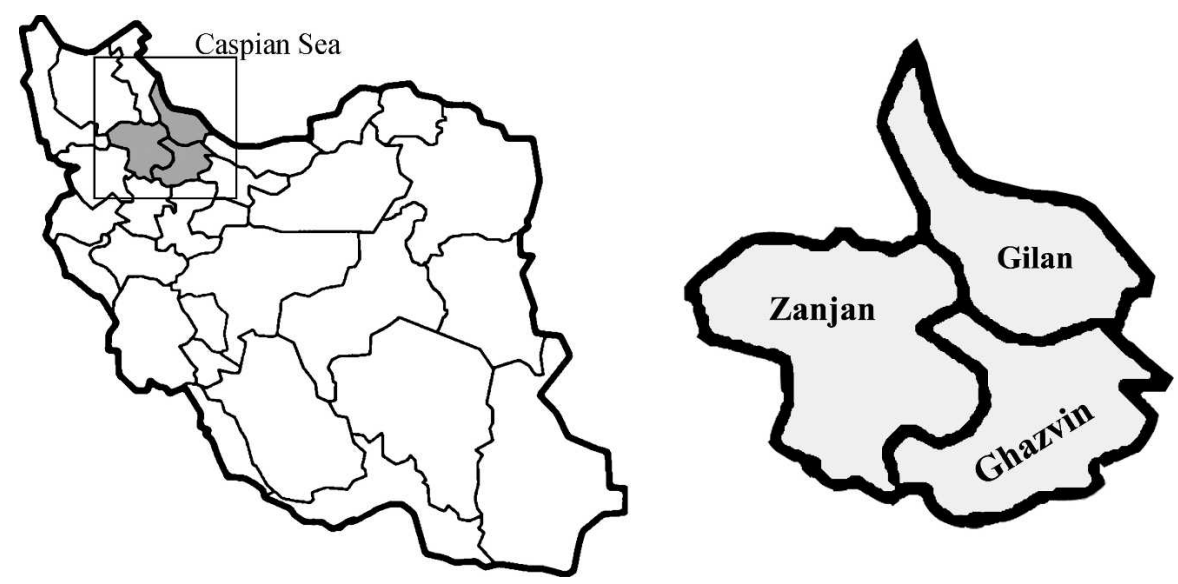

Fig. 1. Iran map showing three provinces of Gilan, Zanjan, and Ghazvin in the north of the country.

identification in the World Germplasm Bank of Córdoba (I. Trujillo, unpublished data), although the remaining accessions were analyzed by 13 microsatellite markers of ssrOeUA-DCA3, ssrOeUA-DCA9, ssrOeUADCA11, ssrOeUA-DCA15, ssrOeUA-DCA16, ssrOeUA-DCA18 (Sefc et al., 2000), UDO99011, UDO99-019, UDO99-043, UDO99-024 (Cipriani et al., 2002), GAPU59, GAPU71B, and GAPU101 (Carriero et al., 2002). Amplification of microsatellites was performed in polymerase chain reactions (PCRs) in a total volume $20 \mu \mathrm{L}$ containing 2 ng genomic DNA, $1 \times$ supplied PCR buffer (Biotools, Madrid, Spain), $200 \mu \mathrm{M}$ of each dNTP (Roche, Switzerland), 0.25 unit of Taq DNA polymerase (Biotools), and $0.2 \mu \mathrm{M}$ of forward (fluorescently labeled) and reverse primers. The PCR reaction was carried out on a thermal cycler (Perkin-Elmer-9600, GMI, Ramsey, MN) programmed with a denaturation at $94{ }^{\circ} \mathrm{C}$ for et al., 1980), null alleles frequency (r) (Brookfield, 1996), $H_{0}$, and $H_{E}$ were calculated by Cervus version 2.0 (Marshall et al., 1998) software.

The discriminating power $(D j)$, confusion probability $(C j)$ of each SSR locus (Tessier et al., 1999) as well as the probability of identity (PI) (Paetkan et al., 1995) were computed. Genetic distances between all pairwise combinations of the accessions were calculated using Dice coefficients. Grouping of the genotypes was determined by using the unweighted paired group using average (UPGMA) method as well as ordination based on principal coordinate analysis ( $\mathrm{PCO}$ ) (Chatfield and Collins, 1995; Ingrouille, 1986). Cophonetic correlation was also determined for different clustering methods. NTSYS-pc version 2.02 (Rohlf, 1998) software was used for these statistical analyses.

\section{Results and Discussion}

Simple sequence repeat diversity in Iranian olive cultivars. The initial screening with five primers (ssrOeUA-DCA3, ssrOeUA-DCA9, ssrOeUA-DCA16, ssrOeUADCA18, and UDO99-043) revealed the presence of the same allelic profiles among different trees (replications) of the same cultivars. So, among 92 accessions, 40 trees could be considered duplications of the plant materials and they were excluded from further analysis. The identification of duplications within and between olive orchards is very important for better management of olive genetic resources in the collections. Table 2 indicates the genetic diversity found by means of 13 SSR on 52 olive accessions belonging to 10 Iranian cultivars. All 13 microsatellite markers except UDO99-019 were polymorph, revealing the presence of 72 alleles in all cultivars analyzed. The number of alleles in each locus varied from one (UDO99-19) to 10 (DCA9) with an average number of 5.6 alleles per locus (Table 2). The allele 174 base pair at DCA18 locus showed the highest frequency (0.62) (data not shown), whereas the lowest frequency (0.01) was observed as unique alleles at eight loci, which is given in Table 3 .

High variability in average number of alleles per locus in olive cultivars has been also reported by other workers (Belaj et al., 2004; Carriero et al., 2002; De la Rosa et al., 2002; Khadari et al., 2003) in studies from other geographical locations. They have reported average values of 7.5, 6.4, 5.7, 7.4, and 5.2 alleles per locus related to different numbers of loci in their studies. Variation reported in the number of alleles in olive cultivars by different workers may be related to variation in the loci studied as well as the number of genotypes and their localities (Lopes et al., 2004).

Under the "Hardy Weinberg" equilibrium, the observed heterozygosity varied from 0.000 in monomorphic locus of UDO99019 to 0.976 in DCA11 locus with an average value of 0.660 . The observed heterozygosity at loci DCA3, DCA9, DCA11, UDO99-43, 
Table 2. Allele size, number of alleles, unique alleles, and heterozygosity indices for studied cultivars in 13 simple sequence repeat (SSR) primers.

\begin{tabular}{|c|c|c|c|c|c|c|c|c|c|c|c|c|}
\hline Locus & Size range & $\begin{array}{l}\text { No. of } \\
\text { alleles }\end{array}$ & $\begin{array}{l}\text { No. of } \\
\text { unique } \\
\text { alleles }\end{array}$ & $\begin{array}{c}\text { No. of } \\
\text { unique } \\
\text { allele patterns }\end{array}$ & $\begin{array}{c}\text { No. of allele } \\
\text { patterns }\end{array}$ & $H_{O}$ & $H_{E}$ & $\mathrm{PIC}$ & $\begin{array}{c}\text { Probability of } \\
\text { null alleles }\end{array}$ & $D j$ & $C j$ & $P I$ \\
\hline ssrOeUA-DCA3 & $229 / 253$ & 7 & 2 & 3 & 13 & 0.929 & 0.819 & 0.781 & -0.0724 & 0.825 & 0.175 & 0.064 \\
\hline ssrOeUA-DCA9 & $159 / 207$ & 10 & 3 & 3 & 14 & 0.810 & 0.792 & 0.753 & -0.0119 & 0.795 & 0.205 & 0.078 \\
\hline ssrOeUA-DCA16 & $122 / 178$ & 6 & 1 & 3 & 13 & 0.634 & 0.667 & 0.607 & 0.0142 & 0.674 & 0.325 & 0.166 \\
\hline ssrOeUA-DCA18 & $162 / 180$ & 6 & 2 & 3 & 8 & 0.524 & 0.548 & 0.492 & +0.0110 & 0.544 & 0.456 & 0.266 \\
\hline UDO99-043 & $170 / 216$ & 9 & 4 & 6 & 11 & 0.762 & 0.697 & 0.651 & -0.0639 & 0.700 & 0.300 & 0.136 \\
\hline ssrOeUA-DCA11 & $140 / 178$ & 6 & 1 & 1 & 9 & 0.976 & 0.759 & 0.710 & -0.1395 & 0.767 & 0.233 & 0.102 \\
\hline ssrOeUA-DCA15 & $243 / 263$ & 3 & 0 & 0 & 3 & 0.073 & 0.319 & 0.293 & +0.6180 & 0.322 & 0.678 & 0.491 \\
\hline UDO99-011 & $112 / 130$ & 6 & 1 & 2 & 7 & 0.860 & 0.701 & 0.640 & -0.01223 & 0.590 & 0.410 & 0.310 \\
\hline UDO99-019 & 129 & 1 & 0 & 0 & 1 & 0.000 & 0.000 & 0.000 & 0.000 & 0.000 & 1.000 & - \\
\hline UDO99-024 & $166 / 189$ & 5 & 0 & 1 & 8 & 0.488 & 0.667 & 0.597 & +0.1552 & 0.672 & 0.328 & 0.178 \\
\hline GAPU59 & $206 / 216$ & 3 & 0 & 0 & 3 & 0.326 & 0.350 & 0.310 & +0.0935 & 0.353 & 0.647 & 0.463 \\
\hline GAPU71B & $118 / 135$ & 4 & 0 & 1 & 6 & 0.721 & 0.651 & 0.574 & -0.0444 & 0.656 & 0.344 & 0.196 \\
\hline GAPU101 & $189 / 217$ & 6 & 1 & 1 & 11 & 0.814 & 0.767 & 0.721 & -0.0348 & 0.771 & 0.229 & 0.096 \\
\hline Mean $^{2}$ & - & 72 & 15 & 24 & 107 & 0.66 & 0.594 & 0.547 & - & 0.543 & 0.457 & 0.195 \\
\hline
\end{tabular}

${ }^{\mathrm{z} N u m b e r s}$ of alleles, unique alleles, unique allele patterns, and allele patterns are total.

$H_{O}=$ observed heterozygosity; $H_{E}=$ expected heterozygosity; $\mathrm{PIC}=$ polymorphic information content; $D j=$ discriminating power; $C j=$ confusion probability; $P I=$ probability of identity.

UDO99-11, GAPU71B, and GAPU101 was higher than expected. The heterozygosity deficiency found in DCA15, DCA16, DCA18, GAPU59, and UDO99-24 loci, which was nonsignificant based on $\chi^{2}$ test $(P<0.01)$, might be attributable to the presence of null alleles at these loci (Table 2; Ishibashi et al., 1996). The presence of null alleles is a consequence of sequence polymorphisms in the flanking regions of the locus resulting from point mutations or insertion/ deletions (Jones and Ardren, 2003).

Discrimination and identification of Iranian olive cultivars. The study of allelic polymorphism obtained in the present work allows discrimination of $84 \%$ of the olive accessions analyzed by producing unique genotype profiles (Table 3). Meanwhile the microsatellite locus UDO99-43 revealed the highest number of unique alleles (4), whereas some loci did not show any unique alleles (Table 2). Six genotypes possessed unique alleles with 'Dezful' possessing the highest number (8) in DCA3, DCA9, DCA11, GAPU101, UDO99-11, and UDO99-43 loci (Table 3).

Calculated PIC values were in a range from 0.000 to 0.781 in 13 loci. It has been suggested that PIC values greater than 0.5 (for example, ssrOeUA-DCA16, UDO99011, and GAPU71B) are informative markers, whereas loci with PIC values greater than 0.7 (ssrOeUA-DCA3, ssrOeUA-DCA9, ssrOeUA-DCA11, and GAPU101) are suitable for genetic mapping (Bandelj et al., 2004). Therefore, in the present study, nine loci may be considered informative, whereas the other three loci may be used in genetic mapping. The PIC values obtained here are close to the values observed by Bandelj et al. (2004) and Omrani-Sabbaghi et al. (2007).

The power of discrimination of microsatellites varied between 0.000 (UDO99-19) to 0.825 (DCA3) with an average of 0.543 . On the other hand, the lowest confusion probability belonged to DCA3 (0.175) and highest value was obtained for UDO99-19 (1.00) (Table 2). The high discriminatory power of the microsatellite loci examined in this study is comparable with the other studies performed on different olive cultivars (Belaj et al., 2004; Khadari et al., 2003).

The low probability of identical genotypes (PI) observed ranging from 0.064 (DCA3) to 0.491 (DCA15) is considered to be useful in genotype discrimination (Table 2). The total cumulative PI value for this set of markers was $1.2 \times 10^{-9}$, which shows the high discrimination power of the selected primers.

The microsatellite locus UDO99-043 revealed the highest number of polymorphic alleles allowing the identification of six different genotypes (Table 2), whereas the combination of five microsatellites of DCA3, DCA9, DCA16, DCA18, and UDO99-043 identified $84 \%$ of the accessions studied (Table 3).

Therefore, the olive cultivars studied can be well discriminated by using the previously mentioned indices as a result of the presence of a high amount of genetic variability among these cultivars.

Synonymous and homonymous cultivars. Analysis of 13 microsatellites used revealed the presence of both synonyms and homonyms in the genotypes studied. Some cultivars such as 'Khara' and two accessions of 'Rowghani' (1050 and 209) produced identical allelic profiles. Moreover, the accession of 'Rowghani-122' showed the same allelic profiles of two accessions of 'Zard-1107' and 'Zard-1109' (Table 3). Therefore, they may be considered as synonyms or mislabeled accessions as a result of morphological difficulties. The previous studies on Iranian olive cultivars have also revealed such misnaming (Hosseini-Mazinani et al., 2004; Samaee et al., 2003).

On the other hand, several accessions with identical names showed a low level of genetic similarity and were placed in different clusters far from each other in the phenogram obtained in which differences in their microsatellite loci is the reason for the separation of these accessions. Like other Mediterranean countries, homonymy is one of the problems in Iranian olive germplasm. Naming of cultivars have been based on common morphological traits, particularly of the fruit
('Geloleh' = round fruit; 'Mari' = sneaky fruit; 'Khorma zeitoon' = date-shaped fruit), toponymys ('Fishomi', 'Dezful', and 'Dakal'), or practical use of cultivars like 'Rowghani' = oily cultivar. Our results demonstrate that generic names of Iranian olive cultivars include different genotypes. For example, few accessions of 'Rowghani' such as 'Rowghani-1048' and 'Rowghani-367' differed in 10 loci (Table 3). Four accessions of 'Geloleh' (389, 1127, 316, and 497) differed from 10 to 11 loci, whereas the accessions of 'Shengeh-1090' and 'Shengeh-263' differed in 12 loci (Table 3). Therefore, these cultivars may be considered homonyms or mislabeling. Discrimination of homonymous cases in olive germplasm has also been reported by using SSRs and other molecular markers by other workers (Belaj et al., 2001, 2002; Khadari et al., 2003; Mekuria et al., 1999; Rallo et al., 2005; Wiesman et al., 1998). On the other hand, studies on characterization of olive cultivars in Eastern Mediterranean countries also have shown homonymy cases (Belaj et al., 2003a, 2003b; Lopes et al., 2004).

Two accessions of 'Geloleh', i.e., 'Geloleh1117' and 'Geloleh-1122', differed in six loci, whereas accessions of the cultivars 'Dakal', 'Fishomi', 'Zard', and 'Khorma zeitoon' differed in one to two loci. These levels of differences are considered intracultivar polymorphism or somatic mutation occurring in the process of vegetative propagation. The existence of intracultivar variation in Iranian olive has been also reported by OmraniSabbaghi et al. (2007). Future comparison using detailed morphological and agronomical data will shed light if these individuals are different cultivars. According to our results, a new way of naming of Iranian cultivars is needed in which both molecular and morphological information should be included.

Genetic relationships. Different similarity coefficients determined among the cultivars studied showed the highest value of similarity $(r=1.0)$ among eight pairs of accessions (for example, among 'Khara', 'Rowghani-1050', and 'Rowghani-209' also 
Table 3. Allelic composition of studied olive accessions for thirteen microsatellite markers.

\begin{tabular}{|c|c|c|c|c|c|c|c|c|c|c|c|c|c|}
\hline \multirow{2}{*}{$\begin{array}{l}\text { Cultivar } \\
\text { accession }\end{array}$} & \multicolumn{13}{|c|}{ Genotype profiles } \\
\hline & DCA3 & DCA9 & DCA16 & DCA18 & UDO43 & DCA11 & DCA15 & UDO11 & UDO19 & UDO24 & GAPU59 & GAPU71B & GAPU101 \\
\hline Dakal-285 & $243 / 251$ & $184 / 206$ & $122 / 156$ & $162 / 162$ & $174 / 210$ & $144 / 178$ & $243 / 243$ & $112 / 127$ & $129 / 129$ & $185 / 189$ & $206 / 210$ & $121 / 124$ & 193/199 \\
\hline Fishomi-1052 & $32 / 253$ & $170 / 202$ & $122 / 122$ & $174 / 179^{y}$ & $170 / 174$ & $142 / 146$ & $243 / 243$ & $119 / 119$ & $129 / 129$ & $183 / 183$ & $216 / 216$ & $121 / 135$ & $191 / 217$ \\
\hline Fishomi-253 & $2 / 253$ & $170 / 202$ & $122 / 122$ & $174 / 174$ & $170 / 174$ & $142 / 146$ & $243 / 243$ & $119 / 119$ & $129 / 129$ & $183 / 183$ & $216 / 216$ & $121 / 135$ & $91 / 217$ \\
\hline Fishomi-255 & $2 / 253$ & $170 / 199$ & $122 / 122$ & $174 / 174$ & $170 / 174$ & $142 / 146$ & $243 / 243$ & $119 / 119$ & $129 / 129$ & $183 / 183$ & $216 / 216$ & $121 / 135$ & $191 / 217$ \\
\hline 147 & 29/232 & $186 / 199$ & $122 / 122$ & $174 / 174$ & $176 / 176$ & $142 / 146$ & $243 / 243$ & $116 / 127$ & $129 / 129$ & $181 / 183$ & $206 / 216$ & & $1 / 191$ \\
\hline & 29/232 & $190^{\mathrm{y} / 199}$ & $122 / 122$ & $174 / 174$ & $178^{y} / 178$ & $142 / 146$ & $243 / 243$ & $119 / 127$ & $129 / 129$ & $181 / 183$ & $206 / 216$ & $1 / 135$ & $1 / 191$ \\
\hline-1127 & $29 / 243$ & $170 / 170$ & $155 / 155$ & $174 / 174$ & $170 / 174$ & $142 / 178$ & $243 / 245$ & $116 / 119$ & $129 / 129$ & $166 / 181$ & $216 / 216$ & $124 / 124$ & 191/191 \\
\hline & $51 / 253$ & $170 / 186$ & $122 / 176$ & $162 / 174$ & $172 / 174$ & $168 / 178$ & $263 / 263$ & $119 / 127$ & $129 / 129$ & $181 / 181$ & $206 / 216$ & $4 / 124$ & $1 / 199$ \\
\hline & $229 / 232$ & $184 / 186$ & $122 / 176$ & $174 / 174$ & $174 / 174$ & $142 / 178$ & $243 / 245$ & $114 / 127$ & $129 / 129$ & $166 / 183$ & $206 / 216$ & $/ 135$ & $1 / 217$ \\
\hline & $9 / 232$ & $186 /$ & 122 & & & & & & & & 216 & 135 & 191 \\
\hline & $9 / 243$ & $170 / 1$ & $176 / 176$ & 166 & & & 243 & & & & 216 & & \\
\hline $\begin{array}{l}Z \\
\text { ho }\end{array}$ & $243 / 253$ & $170 / 202$ & $155 / 178$ & $174 / 174$ & $170 / 172$ & & - & & & & & & \\
\hline$n-1135$ & $243 / 253$ & $170 / 202$ & $155 / 176$ & $174 / 181^{y}$ & $170 / 172$ & $142 / 168$ & $243 / 243$ & $116 / 127$ & $129 / 129$ & $181 / 181$ & $216 / 216$ & $124 / 124$ & $191 / 197$ \\
\hline & $243 / 253$ & $170 / 202$ & $122 / 156$ & $174 / 174$ & $170 / 172$ & $142 / 168$ & $243 / 243$ & $116 / 127$ & $129 / 129$ & $181 / 181$ & $216 / 216$ & $124 / 124$ & $191 / 197$ \\
\hline & & & & & & & & & & & & & \\
\hline Z & $29 / 253$ & & & & & & & & & & & & $191 / 217$ \\
\hline $0 n-402$ & $2 / 243$ & & $122 / 176$ & & & & & & & & 216 & & $191 / 193$ \\
\hline & & & $122 / 176$ & & & & & & & & & & /193 \\
\hline Mari-368 & $232 / 251$ & $186 / 186$ & 176 & $166 / 174$ & $172 / 174$ & $142 / 168$ & $243 / 243$ & $119 / 127$ & $129 / 129$ & $166 / 166$ & $216 / 216$ & $124 / 135$ & $193 / 193$ \\
\hline & $229 / 253$ & $186 / 202$ & 76 & & 176 & & 243 & & & & /216 & & 191/193 \\
\hline & 3 & & & & & & & & & & 216 & & 193 \\
\hline & & & & & & & & & & & & & $197 / 217$ \\
\hline & & & & & & & & & & & & & \\
\hline & $9 / 251$ & & & & & & & & & & 216 & & /191 \\
\hline & & & & & & & $263 / 263$ & & & & & & \\
\hline Shengeh-1115 & $3 / 253$ & $170 / 202$ & $155 / 176$ & $174 / 174$ & $170 / 172$ & $142 / 168$ & - & & $129 / 129$ & 181/181 & $216 / 216$ & $1 / 124$ & $1 / 197$ \\
\hline Shengeh-1089 & $51 / 251$ & $170 / 170$ & $122 / 122$ & $166 / 174$ & $172 / 174$ & $146 / 178$ & $243 / 243$ & & $129 / 129$ & $183 / 183$ & $216 / 216$ & 1/124 & $197 / 217$ \\
\hline & & & $122 / 176$ & & & & & & & & & & \\
\hline & & & & & & & $263 / 263$ & & & & & & 199 \\
\hline & $9 / 232$ & & & & & & - & & & & & & 1/199 \\
\hline Shengeh-1102 & $2 / 253$ & & $122 / 155$ & $174 / 174$ & $172 / 174$ & $142 / 146$ & $243 / 243$ & & & & $/ 216$ & 124 & $7 / 217$ \\
\hline & $229 / 232$ & $170 / 186$ & 178/178 & $166 / 174$ & $174 / 174$ & $142 / 146$ & $243 / 243$ & $119 / 119$ & $129 / 129$ & $183 / 183$ & $216 / 216$ & $121 / 135$ & $193 / 217$ \\
\hline Zard-322 & $229 / 232$ & $170 / 186$ & $122 / 176$ & $166 / 174$ & $172 / 174$ & $142 / 146$ & $243 / 243$ & $119 / 119$ & $129 / 129$ & 183/183 & $216 / 216$ & $121 / 135$ & $193 / 217$ \\
\hline & $229 / 232$ & & $176 / 176$ & & & & & & & & & & $193 / 217$ \\
\hline Zard-1109 & $229 / 232$ & $170 / 186$ & $176 / 176$ & $166 / 174$ & $174 / 174$ & $142 / 146$ & $243 / 243$ & $119 / 119$ & $129 / 129$ & $183 / 183$ & $216 / 216$ & $121 / 135$ & $193 / 217$ \\
\hline
\end{tabular}

${ }^{\mathrm{z}}$ Missing data.

yUnique alleles.

Unique allelic patterns are shown in bold. More than one tree with the same genotype profile is shown in italics.

between 'Zard-1107' and 'Rowghani-122'). The lowest value of similarity occurred between 'Dezful' and 'Rowghani-376' and also between 'Dezful' and 'Khorma zeitoon1135 ' $(\mathrm{r}=0.136)$.

Data obtained from 13 SSR markers were used for elucidating the genetic relationships among olive cultivars by constructing the UPGMA clustering method (Fig. 2). The cophonetic coefficients determined for different clustering methods revealed the highest value for UPGMA $(r=0.86)$ indicating good fit of the original data to the clustering. Therefore, results of UPGMA are discussed subsequently.

In general, seven major groups/clusters were identified in cluster analysis. The first major cluster is comprised of 'Dezful' and 'Dakal' accessions in which 'Dakal' accessions showed higher similarity and were placed close to each other. This result was also observed by Omrani-Sabbaghi et al. (2007). The same is true for two cultivars,
Zard and Fishomi, because they were shown to be similar to each other in our study. These two cultivars formed the second major cluster. This cluster also included a pair of synonymous/mislabeled accessions (Zard1107, 1109, and Rowghani-122) (Fig. 2).

Accessions of 'Geloleh' along with specimens from 'Shengeh' formed the third major cluster.

The accessions of 'Geloleh', 'Rowghani', and 'Shengeh' are distributed in different 
clusters possibly as a result of their genetic variability or misnaming (Table 3 ). Intracultivar variations have also been reported in 'Shengeh' by using morphological characters (Hosseini-Mazinani et al., 2004). Accessions of 'Mari' showed similarity to each other and have been placed in cluster 4 , whereas accessions of 'Khorma zeitoon', 'Rowghani', and 'Shengeh' have been also included. Accession of 'Khara' along with two accessions of 'Rowghani' (1050 and 209) have been also grouped in this cluster. Grouping of such a mixture of accessions may be the result of the presence of synonymous/mislabeled accessions. One accession of 'Geloleh-316' formed cluster 5, whereas cluster 6 consisted of two accessions of 'Rowghani-112' and 'Row- ghani-119'. Accessions of 'Khorma zeitoon' mainly have been placed in cluster 7 along with two accessions of 'Geloleh' and 'Rowghani' and four accessions of 'Shengeh' also included in this cluster.

In the present work, all of the clusters included accessions (except cluster 1) are from three northern provinces of Iran (Gilan, Zanjan, and Ghazvin). Cluster 1 included 'Dakal' and 'Dezful' cultivars, which are mainly cultivated in the south of Iran and have been introduced in the north of the country. Therefore, it may be suggested that separation of these two cultivars from the others may be the result of their adaptation to the environmental and cultivation practices available in the south of the country. A sim-

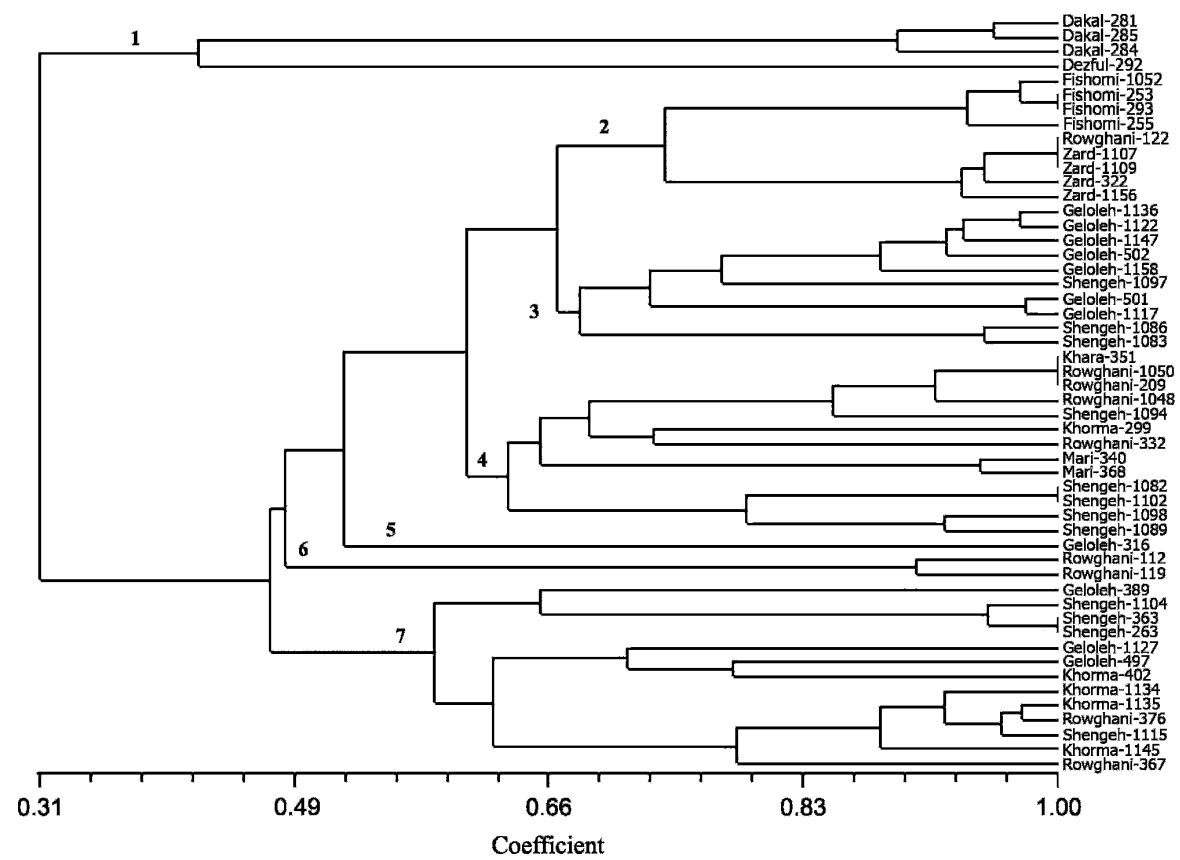

Fig. 2. Unweighted paired group using average dendrogram of Iranian olive cultivars based on Dice's coefficient.

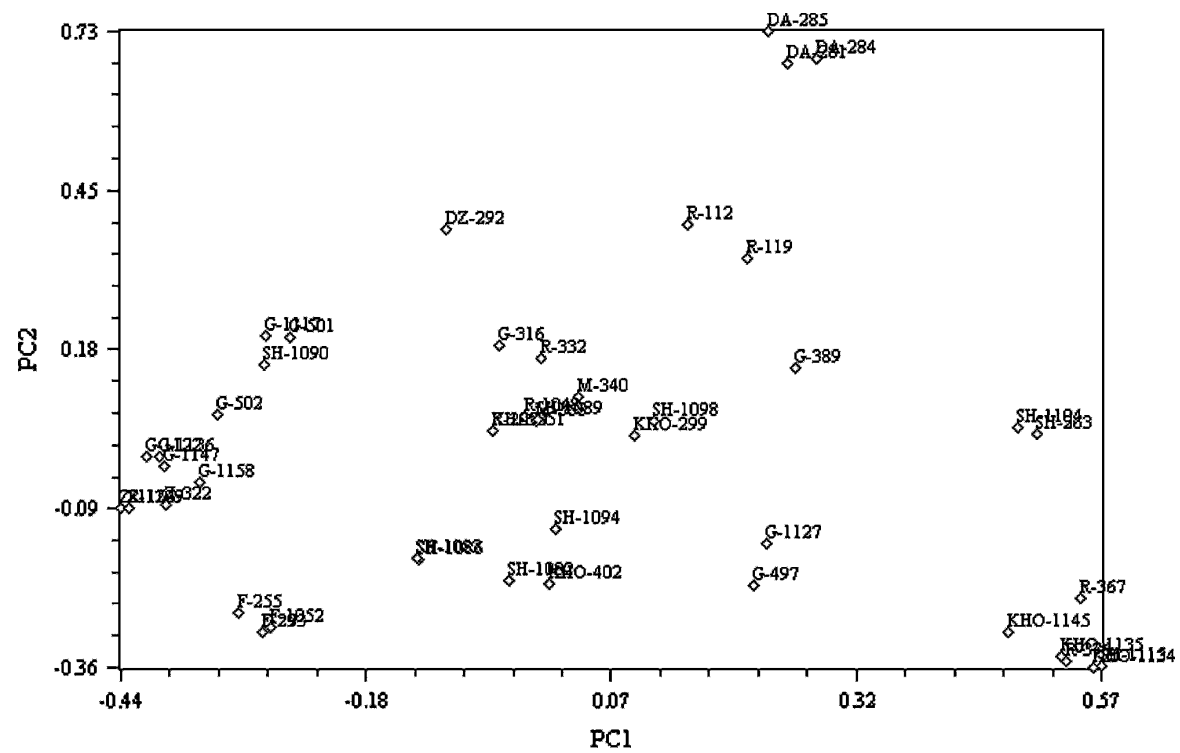

Fig. 3. Principal coordinate analysis of the studied olive cultivars based on simple sequence repeat markers. $\mathrm{DA}=$ Dakal; $\mathrm{DZ}=$ Dezful; $\mathrm{F}=$ Fishomi; $\mathrm{Z}=\mathrm{Zard} ; \mathrm{G}=$ Geloleh; $\mathrm{SH}=$ Shengeh; $\mathrm{KHA}=$ Khara; $\mathrm{R}=$ Rowghani; $\mathrm{M}=$ Mari; $\mathrm{KHO}=$ Khorma zeitoon. ilar result has also been revealed by RAPD analysis of the same genotypes reported earlier (Samaee et al., 2003).

The stability of the groups was also confirmed by partitioning the variants of data sets using PCO. The first and second principal components accounted for $21.5 \%$ and $14.2 \%$ of total variation, respectively. Generally, the PCO plot supported the clustering results obtained (Fig. 3).

In conclusion, the results of present study are the following: 1) $84 \%$ of olive accessions analyzed were discriminated; 2) genetic variation among and between cultivars was revealed by using 13 SSR markers; 3) synonymy and homonymy cases were identified among the cultivars studied; and 4) the genetic relationship among these olive cultivars was studied. In general, the present study showed the use of SSR markers in identification and discrimination of the olive cultivars under study.

Attempts have been started to improve and develop olive germplasm collection and olive orchards in Iran. Programs such as identification of germplasm, conservation, improvement, development, and finally management of olive orchards will be greatly augmented through accurate identification of the local cultivars. Presently, a large-scale program is underway to examine the degree of diversity of Iranian olive varieties at intraand intercultivar levels using phenotypic characteristics and molecular markers. In the framework of this research program, the studied cultivars have been propagated for planting in three major Iranian olive collections, Zanjan (north), Gorgan (northeast), and Fars (south), for further assessments.

\section{Literature Cited}

Angiolillo, A., M. Mencuccini, and L. Baldoni 1999. Olive (Olea europaea L.) genetic diversity assessed by amplified fragment length polymorphisms. Theor. Appl. Genet. 98:411-421.

Bandelj, D., J. Jakse, and B. Javornik. 2002. DNA fingerprinting of olive varieties by microsatellite markers. Food Technol. Biotechnol. 40:185-190.

Bandelj, D., J. Jakse, and B. Javornik. 2004 Assessment of genetic variability of olive varieties by microsatellite and AFLP markers. Euphytica 136:93-102.

Belaj, A., J.M. Caballero, D. Barranco, L. Rallo, and I. Trujillo. 2003a. Genetic characterization and identification of new accessions from Syria in an olive germplasm bank by means of RAPD markers. Euphytica 134:261-268.

Belaj, A., G. Cipriani, R. Testolin, L. Rallo, and I. Trujillo. 2004. Characterization and identification of the main Spanish and Italian olive cultivars by simple-sequence-repeat markers. HortScience 39:1557-1561.

Belaj, A., Z. Satovic, H. Ismaili, D. Panajoti, L. Rallo, and I. Trujillo. 2003b. RAPD genetic diversity of Albanian olive germplasm and its relationships with other Mediterranean countries. Euphytica 130:387-395.

Belaj, A., Z. Satovic, L. Rallo, and I. Trujillo. 2002. Genetic diversity and relationships in olive (Olea europaea L.) germplasm collection as determined by random amplified DNA. Theor. Appl. Genet. 105:638-644. 
Belaj, A., I. Trujillo, R. de la Rosa, L. Rallo, and M.J. Gimenez. 2001. Polymorphism and discriminating capacity of randomly amplified polymorphic markers in an olive germplasm bank. J. Amer. Soc. Hort. Sci. 126:64-71.

Besnard, G., C. Breton, P. Baradat, B. Khadari, and A. Berville. 2001. Cultivar identification in olive (Olea europaea L.) based on RAPDs. J. Amer. Soc. Hort. Sci. 126:668-675.

Botstein, D., R.L. White, M. Skolnick, and R.W. Davis. 1980. Construction of genetic linkage map in man using restriction fragment length polymorphism. Amer. J. Hum. Genet. 32:314-331.

Brookfield, J.F.Y. 1996. A simple new method for estimating null allele frequency from heterozygote deficiency. Mol. Ecol. 5:453-455.

Cantini, C., A. Cimato, and G. Sani. 1999. Morphological evaluation of olive germplasm present in Tuscany region. Euphytica 109:173-181.

Carriero, F., G. Fontanazza, F. Cellini, and G. Glorio. 2002. Identification of simple sequence repeats (SSRs) in olive (Olea europaea L.). Theor. Appl. Genet. 104:301-307.

Chatfield, C. and A.J. Collins. 1995. Introduction to multivariate analysis. Chapman and Hall, London.

Chevalier, A. 1948. L'origine de l'olivier cultive et ses variations. Rev. Int. Bot. App. Agr. Trop. 28:1-25.

Cipriani, G., M.T. Marruzzo, R. Marconi, A. Cimato, and R. Testolin. 2002. Microsatellite markers isolated in olive (Olea europaea L.) are suitable for individual fingerprinting and reveal Polymorphism within ancient cultivars. Theor. Appl. Genet. 104:223-228.

De la Rosa, R., C. James, and K.R. Tobutt. 2002. Isolation and characterization of polymorphic microsatellite in olive (Olea europaea L.) and their transferability to other genera in the Oleaceae. Primer note. Mol. Ecol. Notes 2:265-267.

Diaz, A., R. De la Rosa, A. Martin, and P. Rallo. 2006. Development, characterization and inheritance of new microsatellites in olive (Olea europaea L.) and evaluation of their usefulness in cultivar identification and genetic relationship studies. Tree Genetics \& Genomes 2:165-175.

Green, P.S. and G.E. Wickens. 1989. The Olea europaea complex, p. 287-299. In: Tan, K., Hedge, I. (eds.). The Davis \& Hedge Festschrift, Edinburgh: Edinburgh University Press.

Hosseini-Mazinani, S.M., S.M. Samaee, H. Sadeghi, and J.M. Caballero. 2004. Evaluation of olive germplasm in Iran on the basis of morphological traits: Assessment of Zard and Rowghani cultivars. Acta Hort. 634:145-151.

Ingrouille, M.J. 1986. The construction of cluster webs in numerical taxonomic investigations. Taxon 35:541-545.
Ishibashi, Y., T. Saitoh, S. Abe, and C. Yoshida. 1996. Null microsatellite alleles due to nucleotide sequence variation in the grey-sided vole Clethrionomys rufocanus. Mol. Ecol. 5:589-590.

Jones, A.G. and W.R. Ardren. 2003. Methods of parentage analysis in natural populations. Mol. Ecol. 12:2511-2523.

Khadari, B., C. Breton, N. Moutier, J.P. Roger, G. Besnard, A. Berville, and F. Dosba. 2003. The use of molecular markers for germplasm management in a French olive collection. Theor. Appl. Genet. 106:521-529.

Lopes, M.S., D. Mendonca, K.M. Sefc, F.S. Gil, and A. da Camara Machado. 2004. Genetic evidence of intra-cultivar variability within Iberian olive cultivars. HortScience 39:1562-1565.

Marshall, T.C., J. Slate, L. Kruuk, and J.M Pemberton. 1998. Statistical confidence for likelihood-based paternity inference in natural populations. Mol. Ecol. 7:639-655.

Mekuria, G.T., G.C. Collin, and M. Sedgley. 1999. Genetic variability between different accessions of some common commercial olive cultivars. J. Hort. Sci. Biotechnol. 74:309-314.

Morgante, M. and A.M. Olivieri. 1993. PCRamplified microsatellites as markers in plant genetics. Plant J. 3:175-182.

Murry, M.G. and W.F. Tompson. 1980. Rapid isolation of high molecular weight plant DNA. Nucleic Acids Res. 8:4321-4325.

Nei, M. 1987. Genetic distance and molecular phylogeny, p. 193-223. In: N. Ryman and F. Utter (eds.). Population genetics and fishery management. University of Washington Press, Seattle.

Omrani-Sabbaghi, A., M. Shahriari, M. FalahatiAnbaran, S.A. Mohammadi, A. Nankali, M. Mardi, and B. Ghareyazie. 2007. Microsatellite markers based assessment of genetic diversity in Iranian olive (Olea europaea L.) collections. Scientia Horticulturae. 112:439-447.

Paetkan, D., W. Calvert, I. Stirling, and C. Strobeck. 1995. Microsatellite analysis of population structure in Canadian polar bears. Mol. Ecol. 4:347-354.

Powell, W., M. Morgante, C. Andre, M. Hanafey, J. Tingey, and A. Rafalski. 1996. The comparison of RFLP, RAPD, AFLP and SSR (microsatellite) markers for germplasm analysis. Mol. Breed. 2:225-238.

Rafalski, J.A., J.M. Vogel, M. Morgante, W. Powell, C. Andre, and S.V. Tingey. 1996. Generating and using DNA markers in plants, p. 75-134. In: B. Birren and E. Lai (eds.). No mammalian genomic analysis. A practical guide. Academic Press, San Diego.

Rallo, L., D. Barranco, J.M. Caballero, C. Del Río, A. Martín, J. Tous, and I. Trujillo. (eds.). 2005. Variedades de Olivo en España. Junta de
Andalucía, MAPA y Ediciones Mundi-Prensa, Madrid.

Rallo, P. 2001. Desarollo y aplicacion de microsatelites en olivo (Olea europaea L.). Universidad de Cordoba, España, PhD Diss.

Rallo, P., G. Dorado, and A. Martin. 2000. Development of simple sequence repeats (SSRs) in olive tree (Olea europaea L.). Theor. Appl. Genet. 101:984-989.

Rohlf, F.J. 1998. NTSYS-pc. Numerical taxonomy and multivariate analysis system. Version 2.00. Exeter Software, Setauket, NY.

Sadeghi, H. 1992. Cultivation, preservation and harvesting of olive. Publication of the Agricultural Ministry, Tehran, Iran.

Samaee, S.M., Z.S. Shobbar, H. Ashrafi, M. Hosseini-Mazinani, and M. Sheidai. 2003. Molecular characterization of olive germplasm in Iran by use of random amplified polymorphic DNA (RAPD): Correlation with phenotypic studies. Acta Hort. 623:169-175.

Sefc, K.M., M.S. Lopes, D. Mendoca, M. Rodrigues Dos Santos, M. Laimer Da Camara Machado, and A. Da Camara Machado. 2000. Identification of microsatellite loci in olive (Olea europaea L.) and their characterization in Italian and Iberian olive trees. Mol. Ecol. 9:1171-1173.

Sheidai, M., S. Vaezi-Joze, Z. H-Shahreiyari, H. Noormohammadi, F. Parsian, and I. Farahane. 2007. Study of genetic diversity in some olive (Olea europaea L.) cultivars by using RAPD markers. Pakistan Journal of Biological Science. 10:2972-2975.

Tessier, C., J. David, P. This, J.M. Boursiquot, and A. Charrier. 1999. Optimization of the choice of molecular markers for varietal identification in Vitis vinifera L. Theor. Appl. Genet. 98:171177.

Trujillo, I., L. Rallo, and P. Arus. 1995. Identifying olive cultivars by isozyme analysis. J. Amer. Soc. Hort. Sci. 120:318-324.

Turrill, W.B. 1951. Wild and cultivated olives. Kew Bull. 3:437-442.

Wiesman, Z., N. Avidan, S. Lavee, and B. Quebedeaux. 1998. Molecular characterization of common olive varieties in Israel and the West Bank using randomly amplified polymorphic DNA (RAPD) markers. J. Amer. Soc. Hort. Sci. 123:837-841.

Zeinanloo, A.A. 2006. The olive industry in Iran, p. 173-181. Recent Advances in Olive Industry. OLIVEBIOTEQ

Zohary, D. and M. Hopf. 1994. Domestication of plants in the Old World: The origin and spread of cultivated plants in west Asia, Europe, and the Nile Valley. p. 137-442. 2nd ed. Oxford: Clarendon Press. 